\title{
What motivates IT professionals? Case of Latvia
}

\author{
Svetlana Gribanova* \\ Turiba University, Graudu 68, Riga, Latvia
}

\begin{abstract}
For successful motivation of professionals, it is important to understand accurately their goals, values and job expectations. Theories of motivation suggest different motives to improve productivity, but their effectiveness is not sufficiently validated in case of IT professionals. This study uses empirical data from online surveys of information technology professionals. The purpose of the study is to identify the factors that motivate professionals to work more efficiently, initiatively and productively. The results of the study show that to effectively solve the problem of motivating IT professionals, it is useful to use different theories of motivation, combine these theories and construct new concepts of motivation.
\end{abstract}

\section{Introduction}

IT professionals in Latvia are a highly demanded professional group. The demand for their services exceeds the supply. Effective management of IT professionals is a challenge for the management of companies, as quality and effectiveness of job performance of IT professionals are difficult to measure, and the result of work cannot be always assessed by a non-IT professional. That is why it is important to study the motivation of IT professionals in order to avoid unnecessary control and ineffective use of management resources.

Motivation can be considered as a psychological state of a person, which makes him work better, determines the intensity and effectiveness of his professional behavior [1]. Of course, motivation is only one of the factors that influences professional behavior. However, this factor is quite important for several reasons.

Firstly, even if motivation to work does not lead to an increase in productivity, desire of a professional itself to work better, to make more effort to do a job, is a benefit for the company. Motivated employees are more likely to succeed and create something important, new, and meaningful than non-motivated employees. Secondly, motivation to professional skills development is necessary for a successful career of professionals, and personal success achieved in the company forms loyalty to this company, increases job satisfaction, reduces staff turnover. Thirdly, if professional success and increase of work efficiency have been the result of positive motivation, then the reoccurrence of motivating incentives can determine subsequent aspirations to achievement. So, understanding of what motivates professionals can help to improve effectiveness of external effects to increase productivity. And finally, it is quite difficult to change behavior of professionals. For doing this, it is necessary to motivate them to acquire new knowledge and critically evaluate their own skills and abilities.

\footnotetext{
${ }^{*}$ Corresponding author: svetlana.gribanova.p@gmail.com
} 
In other words, in order for professionals to work better, they need to be motivated to treat themselves critically and constantly improve. This will automatically increase their productivity [2].

In many studies, for description of motives and incentives of professionals the Theory of goal setting is used [3]. This theory assumes that professionals are motivated to work better when they understand the goals of the company and consider these goals important for themselves. What is more, they understand what they should do and also feel competent in order to achieve these goals.

The Theory of goal setting puts forward two competing hypotheses about what motivates professionals. The first hypothesis suggests that professionals can be well motivated by extrinsic motives, including material rewards. This hypothesis assumes that professionals behave in a rational and predictable way. They set goals, achieve them, realizing what reward they will receive for successful job performance. How effective is extrinsic motivation for IT professionals is a debatable question. However, this hypothesis evidently ignores the fact that professionals may have internal drivers and their values may conflict with set tasks. These tasks may be of no interest for them. The second hypothesis relates to internal, moral rewards and motives such as pride, responsibility, reputation.

Many studies show that, on the one hand, empirical data support both hypotheses. Extrinsic and intrinsic motivation explain some variety of professional behavior. On the other hand, empirical data clearly demonstrate that these motivations are not enough. Productivity depends on the goals people strive for, as well as on their values. Misunderstanding of these goals often leads to a conflict between two sources of motivation.

This study goes beyond the Theory of goal setting and aims to identify the factors leading to successful motivation of IT professionals.

\section{Theories of motivation}

Analysis of literature shows that all theories of motivation can be divided into four groups: content theories, cognitive theories, psychoanalytic theories and environmental theories [2].

Content theories try to explain motivation and professional behavior by people's needs. For example, Herzberg separated needs for recognition and achievement from "hygienic" needs such as wages [4]. He claimed that non-fulfillment of "hygienic" needs causes dissatisfaction, but does not affect motivation. Cognitive theories consider such constructions as expectations, beliefs, goals as motives. Psychoanalytic theories emphasize that people are made to work better by subconscious factors, such as desire for power, egocentrism, desire to become famous, etc. Environmental theories consider corporate culture, relationships in a team, organizational process, working conditions, etc. as motives.

Many researchers state that the main difference between theories of motivation lies in the way how to explain the mutual influence and differences between extrinsic and intrinsic motivation. The most successful attempt to understand this relationship is cognitive evaluative theory [5]. This theory tries to explain how external reward affects intrinsic motivation. In works by Deci and Ryan it is empirically proved that intrinsic motivation decreases as material rewards increase, which suggests that only intrinsic or only extrinsic motivation can be supported [6].

Self-determination theory tries to explain a possible way to strengthen intrinsic motivation with the help of extrinsic motivation, overcoming the contradiction of cognitive evaluative theory [7]. The basic assumption of self-determination theory is that extrinsic motivation can vary depending on degree of professional's autonomy. Material and other external rewards should lead to autonomous (not controlled) motivation. Unlike other theories of motivation, Self-determination theory goes beyond general human motivation and simple dichotomy between intrinsic and extrinsic motivation, which is its advantage. 
Another variant of the cognitive theory is Greenberg's organizational justice theory [8], which claims that for successful motivation, people's expectations should be considered by managers as fair and worthy achievements. In other words, the company's goals should take into account people's expectations and their values.

The purpose of this study was to identify the most effective incentives to motivate IT professionals. The study tested motives from different theories of motivation in order to understand which theory of motivation is more adequate in case of IT professionals. The empirical material for this study is the results of an online survey of IT professionals working in companies located in Latvia, both Latvian and international. The survey was conducted in 2019 on a representative sample. The total sample size is 1200 people. Men made up $77 \%$ of the sample, women - $23 \%$. In the course of the survey, respondents were asked questions about what can make them work more effectively, what affects their job satisfaction, and what may cause them to change their job.

\section{The results of the study}

In the course of the study, the respondents were asked to recall situations when they worked more actively, more intensely and with a greater than usual desire to do their job better. After that, the respondents were asked to answer the question what motivated them to work with great productivity in these situations. The analysis of the results shows (fig.1) that the most common answer is an opportunity to get a material reward for their job. Among all the options received, this answer is $18 \%$. It should be noted that fear of losing this reward (as well as fear of losing a job) was very rarely as a motive $(2.6 \%)$.

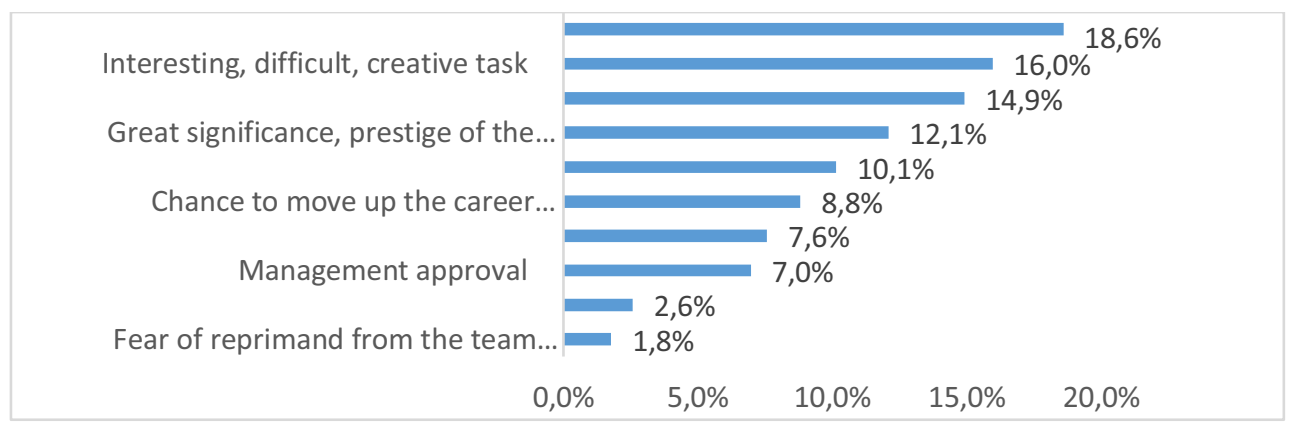

Fig. 1. Motives for job performance

On the whole, motives that can be referred to extrinsic motivation were effective only in $30 \%$ of all situations. In addition to material reward (18.6\%), extrinsic motivation includes a chance to move up the career ladder $(8.8 \%)$, fear of being fired $(2.6 \%)$ and fear of reprimand from the management $(1.8 \%)$.

Intrinsic motivation makes up about $70 \%$ of all motives for better work, and the most common among these motives are desire to solve a difficult task (16\%) and desire to achieve a desired result, to fulfill the set goal (14.9\%). Very close to these motives is a motive connected with awareness of high job importance $(12.1 \%)$, as well as responsibility for job performance $(10.1 \%)$.

Thus, empirical evidence supports the hypothesis that intrinsic motives are more effective to improve productivity of IT professionals. It is important to note that only intrinsic or only extrinsic motives are likely to be ineffective. Despite the fact that IT professionals in Latvia are a highly paid professional group, importance of additional material reward was noted by $56 \%$ of the respondents. 
For revealing factors that affect job satisfaction of IT professionals, during the survey the respondents were asked what could make them change their job and what the company should do to attract good professionals.

Fig. 2 shows the factors that make professionals think about changing their job, i.e., factors that reduce job satisfaction.

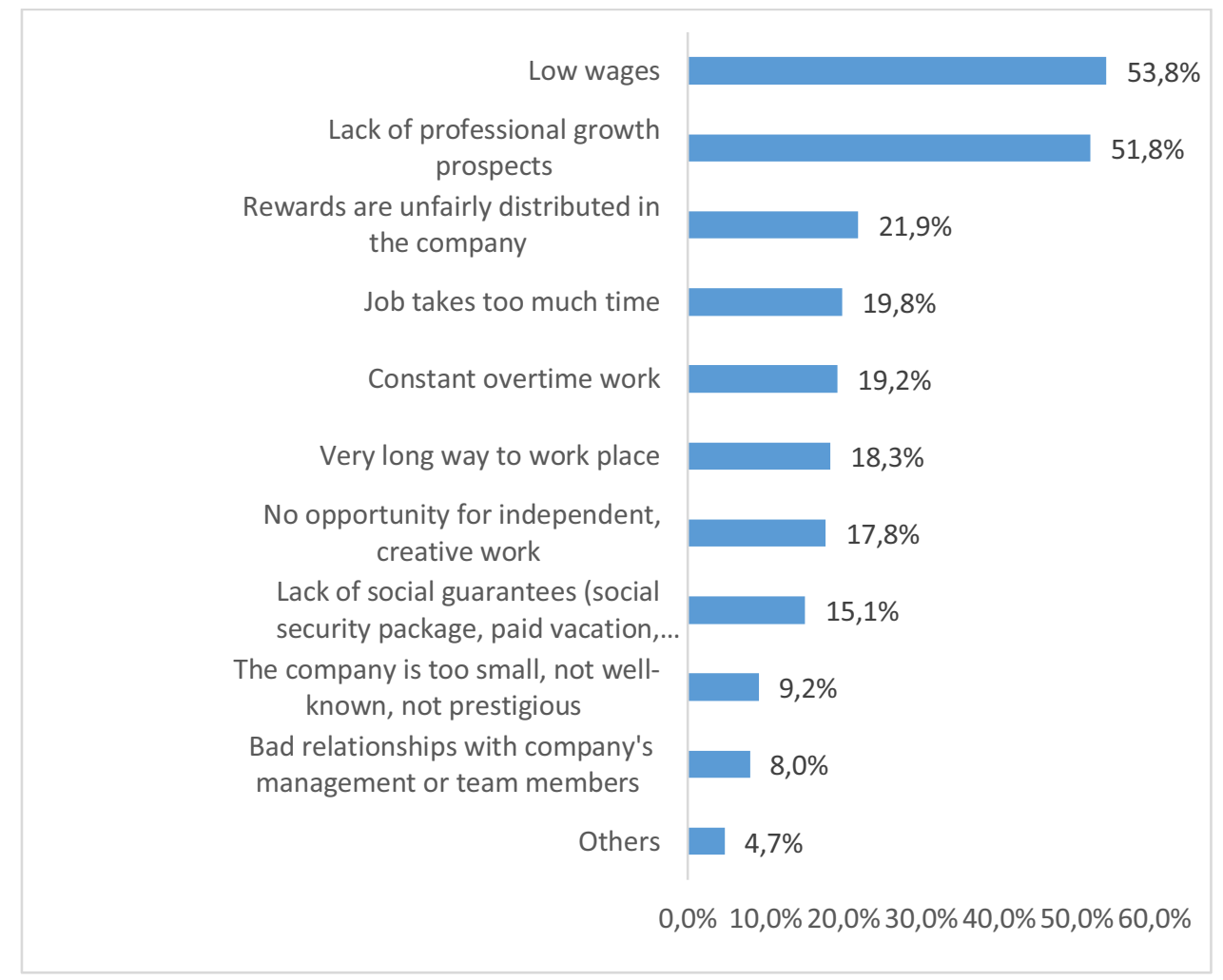

Fig. 2. Reasons for job dissatisfaction

From the data presented in Fig. 2, it is seen that low wages and lack of career prospects are equivalent reasons of changing the job. The differences between them do not exceed the measurement errors $(2.3 \%)$. It can be supposed that a low salary in this case means that an employee receives income that does not allow to solve his material problems or financial tasks he sets. Among IT professionals in Latvia, there is a large number of young and middleaged people who have not yet solved the main material problems.

Lack of professional growth is a problem that is as important as insufficient income. Life goals of professionals consist of self-development, improvement of their professional qualities, involvement in challenging and prestigious work, increase of their authority and reputation. This is exactly the job that brings satisfaction to professionals

A rather important reason for disloyalty to the company is lack of social justice, which is expressed in unfair distribution of resources (21.9\%), lack of social guarantees (15.1\%) and the fact that the company does not value personal time of employees and makes them overwork $(19.2 \%)$. These factors are described in the organizational justice theory which is very rarely used in empirical research.

Answering the question what Latvian companies should do to attract good specialists, $55 \%$ of the respondents said that companies should provide freedom in organization of their 
working hours. Another $30 \%$ of the respondents noted that companies should provide professionals an opportunity to decide themselves how to perform the assigned work. Thus, the results of the study show the influence of the motives described in environmental theories.

The results of the study allow to conclude that companies should offer IT professionals fair wages, an opportunity for self-realization, an opportunity for professional growth, as well as free time to fulfill their needs to be satisfied with their job. All these factors can be used as motives for increasing professionals' work efficiency.

\section{Discussion and Conclusion}

As the results of the study show, it is difficult to explain the motivation of IT professionals within a single theory of motivation. On the one hand, this study and some other studies [9] confirm the conclusion of self-determination theory about importance of a combination of extrinsic and intrinsic motives for successful motivation of professionals [10]. But, on the other hand, this study does not support the conclusion of this theory that extrinsic motives (such as material rewards) increase intrinsic motivation. Material reward is considered by professionals as an opportunity to solve their material problems, and as an expression of social justice. For internal drives, a challenge associated with task complexity is needed, as well as an opportunity to increase self-esteem, increase of your own prestige, and creation of reputation. Material reward does not affect formation of such intrinsic motives.

Some motives for motivating professionals can be explained from the point of view of environmental theory, which says that motivation to work depends on the team, relationship with management, organizational structure, leadership style, etc. The motives that are described in this theory (respect of the team (7.6\%), approval of management $(7 \%)$, fear of reprimand from the team (1.8\%)) make up about $20 \%$ of the entire motivational structure, and are important for $45 \%$ of the respondents.

In addition to this, the study showed importance of organizational justice theory for successful motivation of professionals in Latvia. As noted above, approximately $21 \%$ of the respondents stated unfairness in company's organization as an important reason for changing the job.

Motivating professionals involves a company policy that takes into account complicated interaction of people, their needs, values, personal features, their needs for the environment. Solving this problem requires a more attentive attitude to different theories of motivation, as well as to formation of some combinations of these theories. Probably it is necessary to conceptualize extrinsic motives that are aimed at professional autonomy connected with task setting and choice of ways to solve it. Many theories of motivation require, in case of IT professionals, validation of their assumptions on empirical data, additional research. This will improve quality of professional management, increase number of motivated employees, and, as a result, receive a competitive advantage for the company.

\section{References}

1. G. Latham, C. Pinder. Work motivation theory and research at the dawn of the twentyfirst century. Annu Rev Psychol 56 (2005).

2. S. Buetow. What motivates health professionals? Opportunities to gain greater insight from theory. J of Health Services Research \& Policy , 12, 3 (2007).

3. Ch. Devaux Managing Creative People. What motivators are best suited for the creatives in the creative industries? Thesis (PDF Available) (2017).

4. J. Panday. Managing emotional labor for service employees: An HRM-based approach. Hum. Resour. Manag. Int. Dig. , 26 (2018). 
5. E. Deci, R. Koestner, R. Ryan. A meta-analytic review of experiments examining the effects of extrinsic rewards on intrinsic motivation. Psychol Bull (1999).

6. E. Deci, R. Ryan. Intrinsic Motivation and Self-determination in Human Behavior. New York: Plenium (1985).

7. R. Ryan, E. Deci. Intrinsic and extrinsic motivations: Classic definitions and new directions. Contemporary Educational Psychology, 25 (2000).

8. J. Greenberg. A taxonomy of organizational justice theories. Acad Manage Rev 12 (1987).

9. N. Jankelová, Z. Joniaková, J. Blštáková, I. Némethová. Readiness of human resource departments of agricultural enterprises for implementation of the new roles of human resource professionals. Agric. Econ., 63 (2018).

10. K. Stachova, Z. Stacho, J. Blstakova,, M. Hlatká, L. Kapustina. Motivation of employees for creativity as a form of support to manage innovation processes in transportation-logistics companies. Nase More, 65 (2018). 